\title{
The Relationship of Language and Intelligence Development to the Maturity of the Subcortical Structures in Children with Specific Language Disorders
}

\author{
Victoria L. Efimova ${ }^{a}$, Elena I. Nikolaeva ${ }^{\text {bæ }}$ \\ a Prognoz neurological clinic for children, Saint Petersburg, Russia \\ ${ }^{\mathrm{b}}$ Herzen State Pedagogical University, Saint Petersburg, Russia \\ *Corresponding author: E-mail: klemtina@yandex.ru
}

Objective. To detect possible dysfunctions of subcortical brain structures in children with severe disorders of language development and to study the association of such dysfunctions with linguistic and cognitive development, particularly the development of nonverbal intelligence on the level of the norm.

Design. 45 children with severe speech disorders, aged 4 to 7 years, took part in the study: 9 girls and 36 boys who were patients at the Prognoz neurological clinic for children (Saint Petersburg). The diagnoses according to ICD10 were the following: F.80.1 - expressive speech disorder -35 children; F.80.2 - receptive speech disorder -10 children. The functional state of the brain stem was assessed by the auditory brain stem response (ABR) method. A modified stimulus was used to register peak VI, that is, a short tone burst with a frequency of $4,000 \mathrm{~Hz}$, plateau duration of $0.5 \mathrm{~ms}$, initial front of $0.5 \mathrm{~ms}$, and intensity of $70 \mathrm{~dB}$ above the hearing threshold.

Results. Analysis of the evoked potentials gave the following results: Deceleration of vestibular and/or auditory information conduction on the level of brain stem structures was detected in $98 \%$ of the children. Deceleration of vestibular information conduction was manifested in increased latency of the positive wave P13 cVEMP in comparison with the normative value. Deceleration of auditory information conduction was shown in an increase of the peak intervals of ABRs in comparison with normative values.

Conclusions. All the children displayed conduction disturbances in the auditory and vestibular systems. Conduction disturbances in the auditory system were directly connected with the severity of their speech problems. Conduction disturbances in the vestibular system were associated with lower nonverbal intelligence.

Keywords: cognitive processes, language, subcortical structures of the brain, children, severe disorders of language development 


\section{Introduction}

The terms "cognitive processes" and "language" are entirely associated with the neocortex functions by the majority of researchers, since it is known that evolutionarily it is the cerebral cortex that distinguishes man from other animals. The familiar "horizontal" model of the brain implies analysis of the involvement of the right and left hemispheres in the development of these and other cognitive abilities and the exchange of information between the hemispheres (Friederici, 2012; Hagoort \& Indefrey, 2014). But it does not take into account the contribution of the subcortical structures: the brain stem, the hippocampus, the cerebellum, the basal ganglia, etc. During recent decades, a considerable number of studies have been published that indicate that the subcortical structures take part not only in the movement and conduction of sensory information, but also in cognitive processes such as memory, thinking, and speech (Felix, Gourévich, \& Portfors, 2018; Koziol \& Budding, 2009; Kraus, 2001).

It is obvious that many speech abilities in a small child are quite well developed, despite the immaturity of the cerebral cortex (Werker \& Hensch, 2015), since the neocortex reaches full functional maturity much later than the development of speech and many cognitive functions in normatively developing children. One may assume that structures of a lower order may be involved in a child's cognitive and linguistic development, structures related to the transmission of auditory information and orientation of the body in space. The role of the vestibular system in cognitive development is being actively discussed at the present time (Rine \& Wiener-Vacher, 2013; Wiener-Vacher, Hamilton, \& Wiener, 2013). This is connected with the fact that the brain, as it constructs a picture of the surrounding space, fixes it relative to the position of the head; that is why the vestibular system is active in almost all cognitive processes (Bigelow \& Agrawal, 2015). The role of auditory information is associated with the sensorimotor integration that underlies both the production and understanding of speech (Basu \& Weber-Fox, 2009; Bishop, Hardiman, \& Barry, 2009; Leite, 2014). There are few works that have used auditory brain stem responses (ABRs) to register the deceleration of the auditory signal conduction on the level of the brain stem in children with developmental disabilities (Hornickel, 2011; Leite, Wertzner, \& Matas, 2010) It is known that based on latency, three groups of acoustic evoked potentials are distinguished: short-latent, mid-latent, and long-latent. ABRs are short-latent potentials, fixed within a duration of $10 \mathrm{~ms}$ from the moment of acoustic signal production. This method is used in pediatric neurology for assessment of the integrity and functional maturity of the brain stem structures that participate in conducting auditory information. The absence of ABR components (peaks) or their gross deviation from the norm indicates brain stem dysfunction in the child (Abadi, Khanbabaee, \& Sheibani, 2016; Choudhury \& Benasich, 2011).

The study of ABRs also makes it possible to keep track of the recovery of sensory functions. An increase in the number of registered peaks and the reduction of latent periods indicate restoration of function (Efimov, Efimova, \& Rozhkov, 2015). ABRs are detected even in the prenatal period, in the fetus aged 32-38 weeks. Their parameters allow us to evaluate the neurophysiological maturity of infants. The principal development of ABRs occurs by the age of 12 months, due to the myelination of nerve fibers (Choudhury \& Benasich, 2011). 
Myogenic potentials evoked by clicks are a clinical test of the sacculo-cervical reflex. When the ear is stimulated by a loud click, a stapes movement occurs, and the sacculus receptors of the otolith apparatus are activated. The afferentation passes along the lower vestibular nerve through the vestibulospinal tract and activates the motoneurons of the nucleus of the accessory nerve, which causes contraction of the sternocleidomastoideus muscle. In response to the click, registration of the contraction of the sternocleidomastodeus muscle allows evaluation of the functioning of the sacculus, lower vestibular nerve, and vestibular tract (Cal \& Bahmad, 2009; Murofushi, 2014; Zhou, 2014).

These methods are used to assess the functioning of the otolith apparatus, which allows the organism to sense gravitation, gauge its head position in space, and react to changes in that position. Impairment of the otolith function in adults may lead to full spatial disorientation. In children, most often, vestibular system dysfunction entails deceleration of motor and cognitive development, because the formation of body scheme projections in the cortex and the development of representations about space are performed on the basis of distorted perceptual signals (Rosegren \& Kingma, 2013; Rosengren, Welgampola, \& Colebatch, 2010; Young, 2015).

J. Ayres, the author of sensory integration theory, believed that full-fledged vestibular afferentation, which is an organizing factor for all sensory information, is remarkably important for the cognitive and motor development of the child (Ayres, 1972). Wiener-Vacher et al. (2013) provided evidence of the importance of the vestibular system for the development of cognitive functions in children related to orientation in space. They hypothesized that the loss of vestibular function before the critical stages of development would lead to specific cognitive deficits. Experiments on animals proved that the absence of vestibular stimulation before the critical periods of hippocampus development leads to its atrophy. Wiener-Vacher et al. considered the ages of two, seven, and 11 years to be critical periods for hippocampus development.

Since the otolith organs react not only to vestibular information but also to low-frequency sounds, they are involved in the recognition of the intonation and rhythm of an utterance, which is crucially important for full communication, including language. It has been shown that the sacculus is necessary for speech perception amid background noise. It is also known that during lessons with a speech therapist, vestibular stimulation facilitates speech understanding by the child and enhances his or her speech activity (Ayres, 1972). That is why there is a need for further study of the interrelations between the auditory and vestibular systems (closely connected both anatomically and evolutionarily) and the influence of those interrelations upon a person's cognitive and language development.

One may suppose that part of a child's speech problems may be due, not to processes taking place in an underdeveloped cortex, but to a pathology on the level of the subcortical structures, caused by some peculiarities of the child's development at the earliest stages of ontogenesis, first of all during the prenatal period (Kraus, 2001).

Thus our present investigation sought to detect possible dysfunctions of the subcortical structures in children with severe disorders of language development, and the association of those dysfunctions with the level of language and cognitive development. A fundamental focus in our research is the development of nonverbal intelligence on the level of the norm in those children. 


\section{Materials and Methods}

Forty-five children with severe speech disorders aged from 4 to 7 years took part in the study: 9 girls and 36 boys were patients at the Prognoz neurological clinic for children (Saint Petersburg). The proportion of boys and girls in our sample corresponded to the literature norm, since it is known that speech problems occur in boys more often than in girls (Dodd, 2013).

The diagnoses were verified by a neurologist and a speech therapist. The examinations were conducted at the direction of the neurologist as a diagnostic procedure, with written consent of the parents. The diagnoses according to the ICD-10 were: F.80.1 - expressive speech disorder - 35 children; F.80.2 - receptive speech disorder -10 children. At the time of the study, 22 of the children communicated mostly through vocalization, with a vocabulary of fewer than five words; 12 children used one-word statements and a vocabulary of fewer than 20 words; and 11 children used simple phrases of two words and a vocabulary of more than 20 words.

The functional state of the brain stem was assessed by the auditory brain stem response (ABR), as registered by the NikoletVikingselect-TM analyzer (VIASYS Healthcare, Inc., USA). The following leads were used: mastoid on the left and vertex on the right. Every 500-1,000 evoked responses were summed (each $12 \mathrm{~ms}$ in duration) with no tracks, containing artifacts (automatically withdrawn if the threshold of amplitude discrimination of 30-40 $\mathrm{mW}$ was exceeded). The bandwidth of the signal was set in the range of 100 to $3,000 \mathrm{~Hz}$. A click was used as the stimulus (polarity-rarefaction) with a duration of $0.1 \mathrm{~ms}$ and intensity of $70 \mathrm{~dB}$ of hearing level. The peak latencies and amplitudes of the I, III, and V peaks were measured in the ipsilateral electrode relative to the stimulated ear. The amplitude was gauged in the range from the maximum positive to the maximum negative of the following wave. The time of central conduction was estimated (values of the intervals between waves I-III, III-V, and I-V). The stimuli were presented with headphones (NDH39), separately into the left and right ears, with a frequency of $10.1 \mathrm{~Hz}$.

A modified stimulus was used to register peak VI, that is, a short tone burst with a frequency of $4,000 \mathrm{~Hz}$, plateau duration of $0.5 \mathrm{~ms}$, initial front of $0.5 \mathrm{~ms}$, and intensity of $70 \mathrm{~dB}$ above the hearing threshold. The employment of this modified stimulus made it possible to determine the time of the auditory signal conduction through the brain stem from hair cells of the organ of Corti to the medial geniculate body of the thalamus. Peak VI was identified subject to the detection of peaks I, III, and V, given the standard stimulation. Five hundred to 1,000 representations on the left and right sides were averaged.

Vestibular function was evaluated by the method of cervical vestibular evoked myogenic potential (cVEMP). In response to acoustic stimulation, cVEMPs were registered by the Neuro-EMP-4 neuro-averager (Neurosoft, Ivanovo, Russian Federation). The latency of waves P13 and N23 of VEMP was assessed and registered from the sternocleidomastoideus on the side where the clicks were presented (the sacculo-cervical reflex). The clicks at $130 \mathrm{~dB}$ (ultrasound diagnostics) and $0.5 \mathrm{~ms}$ in duration were delivered by headphone. Four to $20 \mathrm{cVEMPs}$ were averaged in 5 to 15 series with subsequent superposition to assess the reproducibility of the responses. Tonic muscle tension was triggered by the maximum rotation of the head to the side. 
The child was sitting in an armchair during the registration of evoked potentials. None of the children had hearing impairments, according to the audiologists.

J. Raven's colored progressive matrices test was used to assess the intelligence of the subjects, using the Egoskop program facilities of the Medicom research and development company (Taganrog, Russian Federation) for objective testing and analysis. Variant 1 is for children aged 8 to 11 years. It consists of three series of different levels of difficulty, each containing 12 matrices with missing elements. The subject is presented with 36 tasks. Test variants 2 and 3 were used in the present study: variant 2 for children aged $6-8$ years, consisting of two series (A and Av) 24 tasks; variant 3 for children aged 4-6 years, consisting of one series $(\mathrm{A})-12$ tasks. The subject was presented with pictures of figures on a monitor,. One figure was missing; it was presented beneath, among six other figures. The subject's task was to determine the pattern made by the figures in the picture and to indicate which figure was needed to complete the pattern, communicating in any way possible (pointing to it with a finger, putting the cursor on it, or identifying its number). Based on the percentage of correct answers, five levels of the children's intelligence were distinguished:

Level 1 (higher than 95\%) - high intelligence;

Level 2 (75-94\%) -higher than average intelligence;

Level 3 (25-74\%) - medium intelligence;

Level 4 (5-24\%) - lower than average intelligence;

Level 5 (lower than 5\%) - intellectual defect.

All the data were processed with the SPSS-22 software package.

\section{Results}

Analysis of the evoked potentials gave the following results: Deceleration of vestibular and/or auditory information conduction on the level of the brain stem structures was detected in $98 \%$ of the children. Deceleration of vestibular information conduction was manifested in an increase of latency of the positive wave P13 cVEMP in comparison with the normative value. Deceleration of the auditory information conduction revealed itself in an increase of the peak intervals of ABR in comparison with normative values.

Regression analysis of the data was performed. Since nonverbal intelligence was not below average in any of the children, there was no association found between the severity of their speech problems and their nonverbal intelligence.

It was shown that the independent variables cVEMP P13 influenced the dependent variable "nonverbal intelligence". Moreover, since coefficient $\beta$ had a negative value, there was an inverse relationship between the variables. That is, the higher the intelligence, the lower the amplitude of the wave and the greater the speed of vestibular information conduction. One might suppose that nonverbal intelligence was directly connected with the position of the head, which was determined by vestibular characteristics. 
Table 1

Influence of the independent variable upon the dependent variable "nonverbal intelligence"

\begin{tabular}{cccc}
\hline Independent variable & R2 & B & P \\
\hline cVEMP P13 & 0.420 & -0.648 & 0.009 \\
\hline
\end{tabular}

Factor analysis was performed with principal components analysis and the varimax rotation method. The Kaiser-Meyer-Olkin measure of sampling adequacy (KMO) was equal to 0.510 , which indicates the applicability of factor analysis to this sample. A three-factor solution was obtained, with $87 \%$ explained variance.

The total scores on the Raven test and cVEMP P13 (0.862) were included in the first factor with a greater weight $(-0.910)$. This factor might be called the factor of the association between nonverbal intelligence and conduction in the vestibular system: The more effective that conduction, the higher the nonverbal intelligence. The second factor included the ABRs on the right according to the duration of the latent period of peak VI (0.807) and the cVEMPs on the left (0.797). It could be called the factor of unity and interaction of the parameters of the vestibular and auditory systems. The third factor included the peak interval of ABR III-V on the right (0.889) and the severity of speech disturbances (-0.884). This is the factor of the connection of speech impairment to conduction disturbance in the auditory system.

Factor analysis confirmed the data of correlation analysis about the relationship of speech problems to changes of conduction in the auditory system and the relationship of nonverbal intelligence to conduction parameters in the vestibular system. Moreover, it demonstrated the unity of the auditory and vestibular systems.

A statistically significant relationship was found between vestibular disturbances and nonverbal intelligence, as well as between the deceleration of auditory information conduction through the stem structures and the severity of language disorders.

No correlation was found between the severity of language development and the level of intelligence.

\section{Discussion}

We found a statistically significant relationship between the increase of the duration of peak interval III-V ABR and the severity of language disorders. This is consistent with the view that in the absence of speech in a child, the inability to transport stimuli from the surrounding world because of a deficiency in the conducting pathways was relevant, but organic lesions of the brain's cortical linguistic areas (Vizel', 2015) were not. As a result of these impairments, the cortex did not receive the necessary stimulation and could not develop fully. The pathogeny of such dysfunctions has not been studied enough, but it is obvious that if they exist, the child's development occurs on the basis of distorted perceptual information 
(Bishop, Hardiman, \& Barry, 2012; Kraus, 2001; Skoe, Krizman, Spitzer, \& Kraus, 2013; Stefanics, 2011). Thus, disturbance of conduction and primary processing of information in the brain stem could be the reason for derivative cortical dysfunctions.

In a number of studies, the following concept of the bond of the ABR components to the auditory system has been proposed: I — the auditory nerve; II - the cochlear nucleus; III - the core of the superior olive; IV - the lateral loop; V the lower tubercle; VI - the medial geniculate body of the thalamus (Efimov et al., 2014; Leite, 2014). Thus, the deceleration of the auditory signal conduction in the region from the olivary complex to the lower tubercle on the right turned out to be the most significant in our study.

With normal peripheral hearing, the inability of the child to effectively perceive auditory information is called Central Auditory Processing Disorder (CAPD) in the English literature. This term was adopted by the American Speech-LanguageHearing Association (ASHA) in 1996 to denote problems in one or several fields related to the brain's processing of information perceived by the ears: localization of the sound source, differentiation of sounds, recognition of the sequences of sound stimuli, and speed of processing of the auditory information. CAPD may be combined with other dysfunctions, such as language development disorders and specific learning disabilities. The latter were pronounced in children with speech disorders and autism (Moore \& Hunter, 2013; Vandewalle, Boets, Ghesquière, \& Zink, 2012).

Development of the language function in the child depends, first of all, on the coordinated interaction of the afferent and efferent systems, beginning from the auditory nuclei of the lower part of the brain stem and ending with the cerebral cortex (Billiet, 2014); these are regions in which the vestibular and auditory systems interact closely.

According to L.A. Orbeli (1961), the cerebral cortex has no direct connections either to the muscles or to sense organs, and it perceives and transmits signals by means of the spinal cord and the stem structures of the brain. That is why the child's cognitive activity depends not only upon the cortex, but also the whole brain. With functional deficiency of the lower regions of the brain, the CNS is overloaded with "corporeal" information, and cannot fully function and develop (de Quiros \& Schrager, 1978).

Our research confirmed the correlation between the subjects' nonverbal intelligence as assessed by the Raven test and the vestibular function as assessed by the cVEMP method.

It is known that the hippocampus is involved in memory. M.-B. and E. Moser (2008) detected specific neurons in the hippocampus that were called place neurons. Perceiving information from the vestibular system, those cells determine the head position and allow orientation in space, building and memorizing unique "spatial grids". Our data showed that a psychologist has additional techniques for enhancing the intelligence and speech abilities of the preschooler. During the preschool period, the brain is quite flexible. Research on the development of the vestibular apparatus and increasing the conduction efficiency of the auditory system might considerably hasten the development of speech in children with speech disorders. 


\section{Limitations}

Only children with pronounced speech problems participated in our study. A larger sample is needed, including healthy children, but we found it extremely difficult to explain to the parents of those children the importance of such instrumental testing. However, this should be done in future studies.

Further research requires extension of the number of subcortical structures under study, and investigation of the relationship of the cortical and subcortical structures to the development of speech in preschoolers.

\section{Conclusion}

1. In the sample of preschool-age children (4-7 years old), severity of speech problems was not associated directly with nonverbal intelligence.

2. All the children with pronounced speech problems had conduction disturbances in their auditory and vestibular systems.

3. Conduction disturbances in the auditory system were directly connected with the severity of speech problems.

4. Conduction disturbances in the vestibular system were associated with lower nonverbal intelligence.

\section{References}

Abadi, S., Khanbabaee, G., Sheibani, K. (2016). Auditory brainstem response wave amplitude characteristics as a diagnostic tool in children with speech delay with unknown causes. Iranian Journal of Medical Sciences, 41(5), 415-421. Retrieved from https://www.ncbi.nlm. nih.gov/pmc/articles/PMC4967486/pdf/IJMS-41-415.pdf

Ayres, J.A. (1972). Sensory integration and learning disorders. Los Angeles, CA: Western Psychological Services.

Basu, M., \& Weber-Fox, C. (2010). Brainstem correlates of temporal auditory processing in children with specific language impairment. Developmental Science, 13(1), 77-91. https://doi. org/10.1111/j.1467-7687.2009.00849.x

Bigelow, R. T., \& Agrawal, Y. (2015). Vestibular involvement in cognition: Visuospatial ability, attention, executive function, and memory. Journal of Vestibular Research, 25 (2), 73-89. Retrieved from http://www.jvr-web.org/images/JVR25-2Bigelow.pdf

Billiet, C. R., \& Bellis, T.J. (2011). The relationship between brainstem temporal processing and performance on tests of central auditory function in children with reading disorders. Journal of Speech, Language, and Hearing Research, 54(1), 228-242. https://doi.org/10.1044/10924388(2010/09-0239)

Bishop, D. V. M., Hardiman, M. J., \& Barry, J. G. (2012). Auditory deficit as a consequence rather than endophenotype of specific language impairment: Electrophysiological evidence. PLoS ONE, 7(5), e35851. https://doi.org/10.1371/journal.pone.0035851

Cal, R., \& Bahmad, F. (2009). Evoked myogenic potentials: An overview. Brazilian Journal of Otorhinolaryngology, 75(3), 456-462. https://doi.org/10.1590/S1808-86942009000300023

Choudhury, N., \& Benasich, A. A. (2011). Maturation of auditory evoked potentials from 6 to 48 months: Prediction to 3 and 4 year language and cognitive abilities. Clinical Neurophysiology, 122(2), 320-338. https://doi.org/10.1016/j.clinph.2010.05.035 
Dawes, P., \& Bishop, B. (2009). Auditory processing disorder in relation to developmental disorders of language, communication and attention: A review and critique. II. International Journal of Language \& Communication Disorders. 44(4), 440-465. https://doi. org/10.1080/13682820902929073

de Quiros, J.B., \& Schrager, O. (1978). Neuropsychological fundamentals in learning disabilities. San Rafael: Academic Therapy Publications.

Dodd, B. (2013). Differential diagnosis and treatment of children with speech disorder. NY: John Wiley \& Sons. Retrieved from https://books.google.ru/books?id=efOrRCx4H88C\&printsec $=$ frontcover\&hl $=$ ru\&source $=$ gbs_atb $\# \mathrm{v}=$ onepage $\& \mathrm{q} \& \mathrm{f}=$ false

Efimov, O. I., Efimova, V.L., \& Rozhkov, V.P. (2014). Narushenie skorosti provedeniya sluhovoj informacii v strukturah stvola mozga u detej s rasstrojstvami razvitiya rechi i trudnostyami v obuchenii. Sensor. sistemy, 28(3), 36-44.

Felix, R.A., Gourévitch, B., \& Portfors, C.V. (2018). Subcortical pathways: Towards a better understanding of auditory disorders. Hearing Research, 362, 46-60. https://doi.org/10.1016/j. heares.2018.01.008

Friederici, A.D. (2012). The cortical language circuit: From auditory perception to sentence comprehension. Trends Cogn. Sci., 16, 262-268, https://doi.org/10.1016/j.tics.2012.04.001

Hagoort, P., \& Indefrey, P. (2014). The neurobiology of language beyond single words. Annu. Rev. Neurosi., 37, 347-362. https://doi.org/10.1146/annurev-neuro-071013-013847

Hornickel, J. (2011). Auditory brainstem measures predict reading and speech-in-noise perception in school-aged children. Behavioural Brain Research, 216(2), 597-605. https://doi. org/10.1016/j.bbr.2010.08.051

Koziol, L. F., \& Budding, D.F. (2009). Subcortical structures and cognition implications for neuropsychological assessment. New York: Springer. https://doi.org/10.1007/978-0-38784868-6

Kraus, N. (2001). Auditory pathway encoding and neural plasticity in children with learning problems. Audiology \& Neurootology, 6(4), 221-227. https://doi.org/10.1159/000046837

Leite R.A. (2014). Auditory evoked potentials: predicting speech therapy outcomes in children with phonological disorders. Clinics [São Paulo, Brazil], 69(3), 212-218. https://doi. org/10.1111/cdep.12038

Leite, R.A., Wertzner, H.F., \& Matas, C.G. (2010). Long latency auditory evoked potentials in children with phonological disorder [Potenciais evocados auditivos de longa latência em crianças com transtorno fonológico]. Pró-fono : revista de atualização científica, 22(4), 561566. https://doi.org/10.1590/S0104-56872010000400034

Moore, D.R., \& Hunter, L.L. (2013). Auditory processing disorder (APD) in children: A marker of neurodevelopmental syndrome. Hearing, Balance and Communication, 11( 3), 160-167. https://doi.org/10.3109/21695717.2013.821756

Moser, E. I., \& Moser M.-B. (2008). A metric for space. Hippocampus, 18, 1142-1154. https:// doi.org/10.1002/hipo.20483

Murofushi, T. (2014). Vestibular evoked myogenic potential. World Journal of Otorhinolaryngology, 4(2), 6-11. https://doi.org/10.5319/wjo.v4.i2.6

Orbeli, L.A. (1961). Selected works in Vol. 5. Voprosy evolyucionnoj fiziologii. Mocow-Leningrad: Izdatel'stvo ASk SSSR.

Rine, R. M., \& Wiener-Vacher, S. (2013). Evaluation and treatment of vestibular dysfunction in children: Literature review. Neurorehabilitation, 32(3), 507-518. Retrieved from https:// www.researchgate.net/publication/236642398

Rosengren, S. M., \& Kingma, H. (2013). New perspectives on vestibular evoked myogenic potentials. Current Opinion in Neurology, 26(1), 74-80. https://doi.org/10.1097/ WCO.0b013e32835c5ef3 
Rosengren, S., Welgampola, M., \& Colebatch, J. (2010). Vestibular evoked myogenic potentials: Past, present and future. Clinical Neurophysiology, 121, 636-651. https://doi.org/10.1016/j. clinph.2009.10.016

Skoe, E., Krizman, J., Spitzer, E., \& Kraus, N. (2013). The auditory brainstem is a barometer of rapid auditory learning. Neuroscience, 243, 114. https://doi.org/10.1016/j.neuroscience. 2013.03.009

Stefanics, G. (2011). Auditory sensory deficits in developmental dyslexia: A longitudinal ERP study. NeuroImage., 57(3), 723-732. https://doi.org/10.1016/j.ijpsycho.2010.06.350

Vandewalle, E., Boets, B., Ghesquière, P., \& Zink, J. (2012). Auditory processing and speech perception in children with specific language impairment: Relations with oral language and literacy skills. Research in Developmental Disabilities, 33(2), 635-644. https://doi. org/10.1016/j.ridd.2011.11.005

Vizel', T. G. (2015). Nejropsihologicheskij analiz grubyh narushenij rechevogo razvitiya. Vestnik ugrovedeniya, 3, 95-105.

Werker, J.F., \& Hensch, T.K. (2015). Critical periods in speech perception: New directions. Annu. Rev. Psychol., 66, 173-196. https://doi.org/10.1007/s11125-017-9397-6

Wiener-Vacher, S. R., Hamilton, \& D. A., Wiener, S. I. (2013). Vestibular activity and cognitive development in children: Perspectives. Frontiers in Integrative Neuroscience, 7, 92. https:// doi.org/10.3389/fnint.2013.00092

Young, Y. H. (2015). Assessment of functional development of the otolithic system in growing children: A review. International Journal of Pediatric Otorhinolaryngology, 79(4), 435-442. https://doi.org/10.23937/2469-5769

Zhou, G. (2014). Clinical uses of cervical vestibular-evoked myogenic potential testing in pediatric patients. Medicine, 93(4), e37. https://doi.org/10.1097/01.mlg.0000205129.78600.27

Original manuscript received September 14, 2018

Revised manuscript accepted January 10, 2019

First published online February 15, 2019

To cite this article: Efimova, V.L., Nikolaeva E.I. (2019). The relationship of language and intelligence development to the maturity of the subcortical structures in children with specific language disorders. Psychology in Russia: State of the Art, 12(1), 79-88. DOI: 10.11621/pir.2019.0106 